\title{
EL DR. PAUL SCHAUFELBERGER, UN PIONERO DE LA GEOLOGÍA DEL SIGLO XX DE COSTA RICA
}

\author{
Giovanni Peraldo Huertas ${ }^{1 *}$, Jonathan Chinchilla Cortés ${ }^{2} \&$ \\ Teresita Aguilar Álvarez ${ }^{1}$
}

\author{
${ }^{1}$ Escuela Centroamericana de Geología, Universidad de Costa Rica, \\ Apdo. 214-2050, Costa Rica \\ ${ }^{2}$ Departamento de Geología, Ministerio de Obras Públicas y Transportes. \\ *Autor para contacto: gperaldo@geologia.ucr.ac.cr.
}

(Recibido: 24/10/06; aceptado: 02/06/07)

\begin{abstract}
RESUMEN: Se rescatan los aportes del Dr. Paul Schaufelberger quien arribó a Costa Rica en 1929 a instancias del gobierno de la República para que impartiera lecciones de Geología en el Liceo de Costa Rica, en el Colegio Superior de Señoritas y en la Escuela Nacional de Agricultura. En el Centro Nacional de Agricultura ubicado en San Pedro de Montes de Oca, en la actual Ciudad Universitaria Rodrigo Facio, fue director de la Sección de Geología y Mineralogía. En su obra, Schaufelberger aporta material científico y de divulgación sobre la geología que se conocía en ese momento. Escribe mucho material que sirvió como guía para las lecciones relacionadas con el tema de la Geología en Costa Rica. Scahufelberger salió del país en 1938 hacia Colombia, contratado por la Federación de Cafetaleros de ese país con el fin de realizar estudios geológicos dirigidos para mejorar la industria cafetera colombiana. Murió en 1976 en Colombia. Palabras clave: Historia, geología, siglo XX, Schaufelberger, Costa Rica.
\end{abstract}

\begin{abstract}
We highlight the contributions of Dr. Paul Schaufelberger, who arrived to Costa Rica in 1929, contracted by the government, to teach geology at the Liceo de Costa Rica, Colegio Superior de Señoritas and Escuela Nacional de Agricultura. He was the director of the department of Geology and Mineralogy of the Centro Nacional de Agricultura located at San Pedro de Montes de Oca in what is now Ciudad Universitaria Rodrigo Facio. In his work Schaufelberger contributed scientific and disclosure papers about geology as known in his time. He wrote many papers that served as guidance for the lessons related to the subject of Geology in Costa Rica. He left the country in 1939 hired by the Federación de Cafetaleros de Colombia with the purpose of performing geologic field studies intended for the betterment of the Colombian coffee industry. Schaufelberger died in 1976 in Colombia.
\end{abstract}

Key words: History, geology, $20^{\text {th }}$ century, Schaufelberger, Costa Rica. 


\section{INTRODUCCIÓN}

Parte de la investigación en la Escuela Centroamericana de Geología de la Universidad de Costa Rica se ha enfocado en desempolvar trabajos geológicos de finales del siglo XIX y la primera mitad del siglo XX, con el objeto de entender cómo ha sido la evolución de las ciencias geológicas en Costa Rica y evaluar las contribuciones que se han producido. Los actuales conocimientos están cimentados en los esfuerzos de investigación de los pioneros, que con gran esfuerzo y paciencia, construyeron las bases de su ciencia.

El análisis de los aportes científicos del pasado nos enseña que la tecnología es necesaria, pero no es el eslabón fundamental en la cadena del avance y desarrollo científico. Lo necesario es el óptimo conocimiento del bagaje de información del momento, el ahínco por investigar y el amor por el trabajo tesonero, que son las características que hicieron grandes a los científicos del pasado.

\section{ANTECEDENTES DE LA GEOLOGÍA EN COSTA RICAANTES DE SCHAUFELBERGER}

El desarrollo de la geología en Costa Rica repunta después de 1888, con la llegada de naturalistas extranjeros para "apoyar" a los nacionales y con la creación del Instituto Físico Geográfico (IFG), que canalizó la investigación científica hacia algo que se quedara en el país (Alvarado et al., 1991; Alvarado \& Peraldo, 2003). No obstante, la febril actividad científica empezó a declinar a finales de la década de 1910 .

Importantes aportes al conocimiento geológico del país, fueron los trabajos de Romanes (1912) y el equipo geológico dirigido por Donald McDonald entre 1919 y 1920 . Destaca la publicación del mapa geológico para Costa Rica del Dr. Karl Sapper, reproducido por Denyer \& Alvarado (2000). Sin embargo, a lo interno, la actividad de investigación sobre geología decayó con respecto a la sistemática puesta en práctica desde la creación del IFG.

\section{EL INGRESO Y PERMANENCIA DE SCHAUFELBERGER}

Alrededor de 1929, a instancias del gobierno de la República, ingresa al país el Dr. Paul Schaufelberger (Fig. 1), quien firma un contrato con este para atender asuntos relacionados con la enseñanza e investigación del campo geológico en Costa Rica (Ventura \& Sibaja, 1991). El contrato firmado en 1930 por Schaufelberger y Ricardo Fournier, en ese momento secretario de Educación Pública obliga al primero a prestar sus servicios como profesor de Geología en el Liceo de Costa Rica y en el Colegio Superior de Señoritas, que debe cubrir 18 horas semanales en cuatro días seguidos, dará sus lecciones en español y se adaptará a las disposiciones legales y reglamentos de los establecimientos donde cumpla sus servicios. Los restantes días, los dedicará a la investigación científica, en el Instituto Físico Geográfico (IFG) o en el Museo Nacional. También estipula el contrato que el señor Schaufelberger podrá impartir lecciones privadas de geología, cuyo tiempo no exceda de dos horas por día y que no perjudique su labor para el Estado.

El gobierno se obliga a pagar a Schaufelberger la suma de ciento setenta y cinco dólares mensuales o su equivalente en colones y se obliga a asegurarlo en caso de accidente. También se obliga el gobierno a pagarle sus gastos de regreso a Ginebra, Suiza más un suplemento de viaje que asciende a la suma de doscientos francos suizos. Este contrato rige desde el 1 de enero de 1930 hasta el 31 de diciembre de 1933 (Gobierno de Costa Rica, 1931, p. 349). Se revisó el contrato de 1936 y cambia en cuanto al grado de exigencia, pues este nuevo contrato firmado por Schaufelberger y Salvador Umaña Castro, Secretario de Educación Pública, se modifica en cuanto a los servicios que debe prestar el Dr. Schaufelberger, pues se dice que el señor Schaufelberger se obliga a prestar sus servicios como geólogo y profesor en el establecimiento que el gobierno le indique y “...desempeñará 


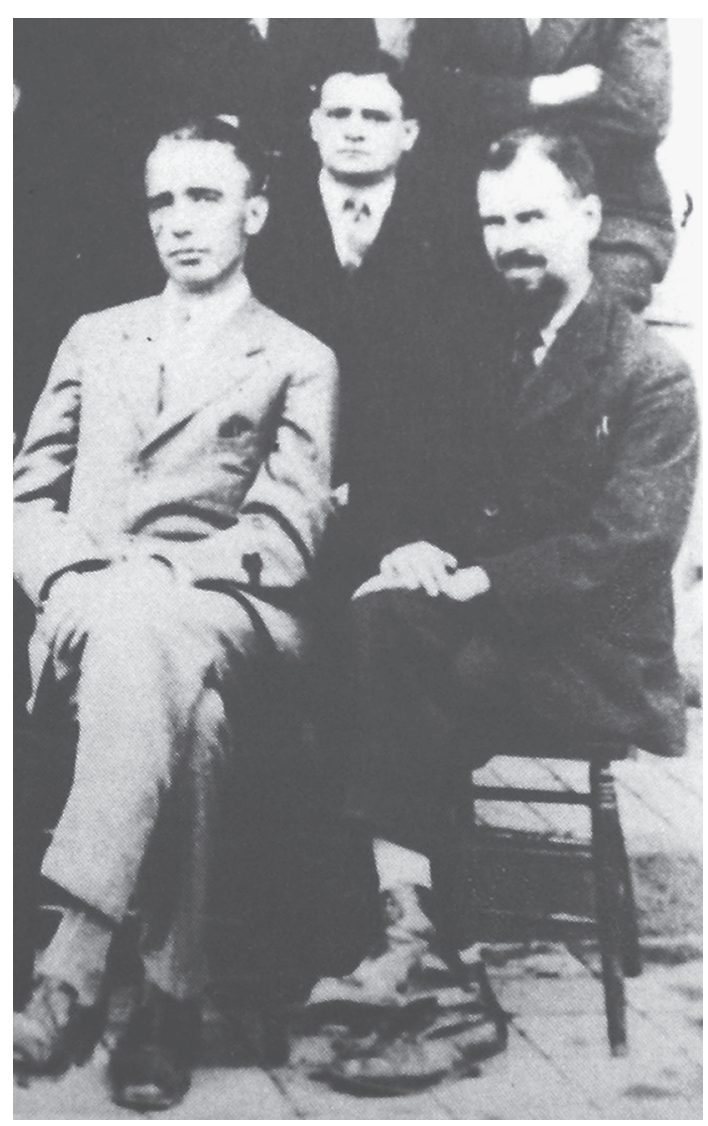

Fig. 1: Fotografía del Dr. Paul Schaufelberger, a la derecha.. Tomada de Porras (1988).

asimismo sin disfrute de emolumento alguno, las comisiones que aquel le diere..." El gobierno pagará el monto de cuatrocientos colones mensuales. Todo lo demás queda igual al firmado en 1930. Este nuevo contrato rige desde el 1 de enero de 1936 hasta el 28 de febrero de 1938 (Gobierno de Costa Rica, 1936). Schaufelberger abandona el país posiblemente en los primeros meses de 1938 para dirigirse a Colombia. No se conocen los motivos por los cuales no se le volvió a contratar, pues revisando las leyes y decretos para el año 1938, nada hay sobre una nueva contratación con el gobierno (Gobierno de Costa Rica, 1938). Ese año coincide con su partida hacia Colombia.

\section{BREVE BIOGRAFÍA DE SCHAUFELBERGER}

Según informes de la Embajada Suiza en Costa Rica (Doris Wälchli Giraud agregada cultural), se sabe que el Dr. Paul Schaufelberger nació el 27 de agosto de 1894 en la localidad de Richterswil, Suiza, hijo de Jacques Schaufelberger. Sus padres vivieron en Meilen, Suiza. Después de trabajar en Costa Rica, viajó a Colombia donde laboró para la Federación Nacional de Cafetaleros con sede en Chinchiná. Falleció en ese lugar el día 30 de agosto de 1976. El Dr. Schaufelberger nunca se casó. Parte de esta información concuerda con la entrevista que los autores hicieron al Dr. Jorge León, quien conoció al Dr. Schaufelberger en Chinchiná, Colombia (ver Apéndice 1). Esto corrige la información de Fernández (1993) quien refiere que el Dr. Schaufelberger se fue a Venezuela después de que partió de Costa Rica, lo cual puede deberse a una equivocación con el caso del Dr. Henri Pittier, pues León (2003) refiere que después de su partida en 1905 de Costa Rica, Pittier radicó en Venezuela hasta su muerte.

No se conocen sus actividades previas a su arribo a Costa Rica, se presume que efectuó trabajos geológicos en Suiza. Sus primeras actividades docentes en el campo de la Geología, tienen lugar en el Liceo de Costa Rica y en el Colegio Superior de Señoritas (Denyer \& Alvarado, 2000). En la Escuela Nacional de Agricultura impartió cursos de mineralogía, geología y petrografía (Castillo \& Peraldo, 2000a, b). También realizó labores de investigación y administrativas en la Sección de Geología del Museo Nacional (Alvarado et al., 1991). En esos años se creó el Centro Nacional de Agricultura, con sede en San Pedro de Montes de Oca, justamente en la finca que años después sería la sede de la Ciudad Universitaria Rodrigo Facio. En este centro, Schaufelberger fue el director de la Sección de Geología y Mineralogía, tal como lo refiere Fernández (1993).

Realizó estudios geológicos en Talamanca y en el Valle del Reventazón. Además, incursionó en estudios sismológicos, pues en 1936 la Sección 
de Geología del Museo Nacional fue trasladada al Centro Nacional de Agricultura en la actual Ciudad Universitaria Rodrigo Facio, en donde el Dr. Schaufelberger puso en funcionamiento un aparato sismológico (Alvarado et al., 1991). Este edificio estuvo donde actualmente se ubica la Escuela de Enfermería de la Universidad de Costa Rica.

La labor del Dr. Schaufelberger fue tanto de divulgación como de investigación geológica, donde destacan sus “Apuntes de Geología”, publicados a partir de 1931 por la Imprenta Universal. Crosby (1945) también destaca los estudios geológicos de Schaufelberger que fueron publicados en Costa Rica. Fernández (1993) refiere que la labor de Schaufelberger fue muy variada, pues escribió desde artículos científicos hasta producción de divulgación científica y material didáctico.

\section{APORTES A LA GEOLOGÍA DE COSTA RICA}

La presencia del Dr. Schaufelberger fue importante para el desarrollo de la ciencia geológica en Costa Rica, pues esta se encontraba deprimida por aquella época. Los geólogos que llegaban al país se establecían únicamente en forma temporal mientras realizaban sus investigaciones y publicaban sus estudios, preferiblemente en el extranjero. La labor intrínseca del Dr. Schaufelberger fue la publicación de sus estudios geológicos en nuestro país, aprovechando para ello la creación de nuevas imprentas en el país, dentro de las que destacan por esa época imprentas tales como la Universal y la Borrasé Hnos., entre otras. Su trabajo en Costa Rica fue productivo, pues se le conocen una serie de publicaciones que las denominó "Apuntes de Geología”, en las que abarca temas que van desde la mineralogía óptica hasta la tectónica y paleontología, tal como se observa en el Cuadro 1. Fue además colaborador en la Revista del Centro Nacional de Agricultura, en donde estuvo a cargo de la sección de Geología y Mineralogía.

Es posible que el Dr. Schaufelberger arribara al país a finales de 1928 o principios de 1929 , y además que prácticamente desde su llegada empezara a investigar, apoyándose en trabajos anteriores, las características de la geología del país en el cual laboraría en docencia e investigación. Sus primeras ideas sobre la geología del país fueron publicadas en su obra "Una noticia sobre la geología de Costa Rica: un perfil del Pacífico al Atlántico", en la que interpreta la existencia en Costa Rica de rocas primitivas (constituidas por rocas ígneas como granitos, sienitas, dioritas y gabros) y describe también las rocas sedimentarias del país como pertenecientes al Cretácico y al Terciario (Schaufelberger, 1929a). En esa misma publicación interpreta: 1. Un horst en la Península de Nicoya y su cordillera. 2. Una fosa en la costa atlántica, y dentro de sus prolongaciones, ubica al Valle Central en ese tiempo llamado meseta- y a los lagos de Nicaragua y Managua. 3. Otra fosa en la costa del Pacífico, dentro de la cual, están los golfos de Nicoya y Dulce. 4. Un levantamiento de la costa del Caribe con base en los corales que forman, junto a los aluviones, la llanura de Limón. 5. Una edad cretácica de unas areniscas existentes entre San Miguel de Desamparados y El Tablazo, con base en el fósil Hippurit (Bivalvo, rudista), en donde existe también una mina de carbón de mala calidad. Posiblemente esta mina de carbón corresponde con una de las facies continentales de la actualmente llamada formación Coris.

Brevemente, Schaufelberger (1929a) esboza la historia geológica de Costa Rica a partir del Arcaico, evolucionando junto a las grandes Américas. El cuadro 2 resume dicha historia geológica apoyada en la figura 2.

Es posible que por esa época tan temprana de su arribo al país, el Dr. Schaufelberger ya hubiera recorrido muchos lugares del Valle Central, a juzgar por su descripción de la geología de Escazú: “...más en el NW el Escasú guarda su secreto bajo una vegetación impenetrable; solamente encontramos en los ríos y los campos algunos bloques de la profundidad..." (Schaufelberger, 1929a). En esta publicación, menciona que los perfiles que realizó para el trabajo (Fig. 2) fueron el resultado de varias excursiones donde se acompañó de Anastasio Alfaro, Charles Borel, Emel Jiménez, W.Lohmann, W. Peters, José Fidel Tristán, y M. Valerio. 


\section{Cuadro 1}

Publicaciones que el Dr. Paul Schaufelberger escribió como profesor de geología del Colegio Superior de Señoritas y el Liceo de Costa Rica durante su estancia en el país.

\begin{tabular}{|c|c|c|c|c|}
\hline TÍTULO & EDITORIAL/IMPRENTA & $\begin{array}{l}\text { NÚMERO DE } \\
\text { PÀGINAS }\end{array}$ & ILUSTRACIONES & AÑO \\
\hline Tablas mineralógicas y geológicas & Imprenta Universal & 9 págs. & Perfiles, mapa geológico, columnas. & 1929 \\
\hline $\begin{array}{l}\text { Una noticia sobre la geología de Costa } \\
\text { Rica: un perfil del Pacífico al Atlántico. }\end{array}$ & $\begin{array}{l}\text { Revista del Colegio Superior } \\
\text { de Señoritas }\end{array}$ & 12 págs. & $\begin{array}{l}\text { Perfiles geológicos y secciones delgadas } \\
\text { de roca. }\end{array}$ & $\begin{array}{c}12 / \\
1929\end{array}$ \\
\hline Apuntes de Geología: El suelo. & Imprenta Universal & 13 págs. & - & s.f. \\
\hline Costa Rica & Imprenta Universal & 83 págs. & $\begin{array}{l}\text { Varias sobre mineralogía óptica, per- } \\
\text { files y columnas geológicas, fotos y } \\
\text { grabados sobre diferentes aspectos } \\
\text { volcánicos, láminas con esquemas de } \\
\text { fósiles del país. }\end{array}$ & 1931 \\
\hline $\begin{array}{l}\text { Apuntes de Geología: Cráteres parási- } \\
\text { tos del Macizo Volcánico }\end{array}$ & $\begin{array}{l}\text { Revista Estudios, Ns. } 3 \text { y } 4 . \\
\text { Imprenta Trejos Hnos. }\end{array}$ & 11 págs. & - & 1931 \\
\hline $\begin{array}{l}\text { Apuntes de Geología: El origen de las } \\
\text { fuentes termales y minerales de la Me- } \\
\text { seta Central. }\end{array}$ & $\begin{array}{l}\text { Revista El Maestro, N 9, tomo } \\
\text { V. }\end{array}$ & 8 págs. & - & $\begin{array}{c}05 / \\
1931\end{array}$ \\
\hline $\begin{array}{l}\text { Über einige Mineral - und Ther- } \\
\text { malquellen von Costa Rica }\end{array}$ & $\begin{array}{l}\text { Buchdruckerei Emil Birkhäus- } \\
\text { er \& Cie. Basel. Eclogae geo- } \\
\text { logicae Helvetiae, Vol. 25, N } \\
1 .\end{array}$ & 139 a la 162 & - & 1932 \\
\hline $\begin{array}{l}\text { Apuntes de geología: La historia del } \\
\text { valle del Río Grande de Tárcoles. }\end{array}$ & $\begin{array}{l}\text { Revista Ciencia, Año IV, N } \\
27 \text {, órgano de la Sociedad } \\
\text { Científica de Costa Rica. Im- } \\
\text { prenta Ujueta. }\end{array}$ & 8 a la 10 & 2 perfiles geológicos. & $04 / 1932$ \\
\hline $\begin{array}{l}\text { Un estudio elemental sobre la geología } \\
\text { de Costa Rica }\end{array}$ & $\begin{array}{l}\text { Revista La Escuela Costarri- } \\
\text { cense, N 3, año } 1\end{array}$ & 56 págs. & $\begin{array}{l}4 \text { perfiles geológicos, perfil geológico } \\
\text { del Macizo volcánico central, Valle } \\
\text { del Reventazón, } 1 \text { mapa geológico de } \\
\text { Costa Rica. }\end{array}$ & $\begin{array}{c}13 / 06 / \\
1932\end{array}$ \\
\hline $\begin{array}{l}\text { Über einige Mineral - und Ther- } \\
\text { malquellen von Costa Rica , II }\end{array}$ & $\begin{array}{l}\text { Buchdruckerei Emil Birkhäus- } \\
\text { er \& Cie. Basel. Eclogae geo- } \\
\text { logicae Helvetiae, Vol 26, N } \\
2 .\end{array}$ & 281 a la 294 & - & 1933 \\
\hline $\begin{array}{l}\text { Apuntes de Geología: Algunas nocio- } \\
\text { nes sobre terremotos y temblores en } \\
\text { Costa Rica }\end{array}$ & $\begin{array}{l}\text { Publicaciones del Liceo de } \\
\text { Costa Rica, Imprenta La Tri- } \\
\text { buna. }\end{array}$ & 3 a la 13 & $\begin{array}{l}1 \text { bloque diagrama que muestra la propa- } \\
\text { gación de las ondas sísmicas en la cor- } \\
\text { teza terrestre. } \\
1 \text { perfil que muestra temblores eruptivos } \\
\text { y volcánicos. } \\
1 \text { fotografía sobre la erupción de junio de } \\
1933 \text { del volcán Irazú. } \\
1 \text { mapa de las isosistas del terremoto del } \\
22 \text { de marzo de } 1933 \text {. }\end{array}$ & 1933 \\
\hline $\begin{array}{l}\text { Apuntes de Geología: Un estudio ge- } \\
\text { ológico de la Meseta Central - Occi- } \\
\text { dental }\end{array}$ & $\begin{array}{l}\text { Revista del Instituto de De- } \\
\text { fensa del Café/ Imprenta Bor- } \\
\text { rasé Hnos. }\end{array}$ & 15 págs. & - & 1935 \\
\hline $\begin{array}{l}\text { Algunos datos sobre la geología de San } \\
\text { Ramón y sus alrededores }\end{array}$ & $\begin{array}{l}\text { Revista La Escuela Costarri- } \\
\text { cense, N 9, año II }\end{array}$ & 33 págs. & $\begin{array}{l}1 \text { perfil geológico Atenas - San } \\
\text { Ramón, otro Naranjo - San Ramón, } \\
\text { otro de Cebadilla, otro de San Pablo } \\
\text { - Las Quebradas. }\end{array}$ & \\
\hline
\end{tabular}




\begin{tabular}{|c|c|c|c|c|}
\hline $\begin{array}{l}\text { Apuntes de Geología: Algunos datos } \\
\text { meteorológicos de Costa Rica: }\end{array}$ & $\begin{array}{l}\text { Números } 3 \text { y } 4 \text { de la Revista } \\
\text { del Centro Nacional de Agri- } \\
\text { cultura, San Pedro de Mon- } \\
\text { tes de Oca. Imprenta de Juan } \\
\text { Arias. }\end{array}$ & 36 a la 54 & - & $\begin{array}{c}\text { Marzo y } \\
\text { abril de } \\
1936\end{array}$ \\
\hline $\begin{array}{l}\text { El calcio: La caliza apuntes de Geología } \\
\text { n } 12\end{array}$ & $\begin{array}{l}\text { Centro Nacional de Agricul- } \\
\text { tura, San Pedro de Montes de } \\
\text { Oca. Imprenta de Juan Arias }\end{array}$ & 22 págs. & 1 el ciclo del calcio & $\begin{array}{c}\text { enero de } \\
1937\end{array}$ \\
\hline
\end{tabular}

\section{Las “Tablas Mineralógicas y Geológicas", publicación de 1929}

La labor de Schaufelberger desde su llegada al país fue muy intensa, pues ya en 1929, publicó un trabajo geológico dirigido a la enseñanza secundaria que se tituló “Tablas Mineralógicas y Geológicas”, editado por la Imprenta Universal en San José. Sin embargo, dado el poco tiempo existente entre el posible arribo de Schaufelberger al país y la fecha de publicación del trabajo mencionado, resulta difícil que la información geológica presentada haya sido en su totalidad producto del trabajo de campo efectuado por Schaufelberger. Es muy probable que haya recurrido a información existente en el país para la década de 1920 y producida por algunos eruditos como Gustavo Michaud, Juan de Dios Céspedes, Luis Matamoros, Paul Biolley, Miguel Obregón, Pedro Nolasco, José Fidel Tristán, Anastasio Alfaro, entre otros, todos

Cuadro 2

Historia geológica de Costa Rica, según Schaufelberger (1929a).

\begin{tabular}{|c|c|c|}
\hline ERA / PERIODO & PRINCIPALES HECHOS GEOLÓGICOS & $\begin{array}{l}\text { NÚMERO DE } \\
\text { PERFIL EN FIG. } 2\end{array}$ \\
\hline Arcaico & $\begin{array}{l}\text { Formación de las rocas primitivas en capas } \\
\text { paralelas. Visión paleogeográfica de América } \\
\text { como un continente reunido. Un primer plega- } \\
\text { miento forma la cordillera de Talamanca. }\end{array}$ & 1 \\
\hline Pérmico al Cretácico & $\begin{array}{l}\text { Formación de otro conjunto de pliegues co- } \\
\text { munes en América Central, especialmente en } \\
\text { la América norte (septentrional?) } \\
\text { Costa Rica era continente (en la publicación de } \\
1929 \text { se dice “...el país era tierra...”), pero la } \\
\text { erosión fue desgastando hasta la línea a del perfil } \\
\text { 2. En el Cretácico, el mar inundó el continente y } \\
\text { se formó el paso interoceánico. Se comenzaron } \\
\text { a depositar sedimentos. Indica que antes del } \\
\text { Triásico empezó la separación del continente. }\end{array}$ & 2 \\
\hline Terciario & $\begin{array}{l}\text { Empieza un levantamiento que originará el } \\
\text { puente de tierra entre las dos Américas. El } \\
\text { borde del Atlántico se disuelve quedando las } \\
\text { islas del Caribe. }\end{array}$ & 3 \\
\hline Mioceno Inferior & $\begin{array}{l}\text { Grandes movimientos de la costra terrestre } \\
\text { y un volcanismo profuso, iniciaron las erup- } \\
\text { ciones de la cordillera (suponemos que es la } \\
\text { Central) y en la fosa atlántica intruyeron los } \\
\text { granitos de Escazú. El volcanismo cubrió con } \\
\text { sus materiales grandes áreas y empezó el hun- } \\
\text { dimiento de las fosas }\end{array}$ & 4 \\
\hline Cuaternario (conocido en los perfiles como Aluvio) & Se formó el horst del centro del país. & 5 \\
\hline
\end{tabular}




\section{Perfiles de Costa Rica.}

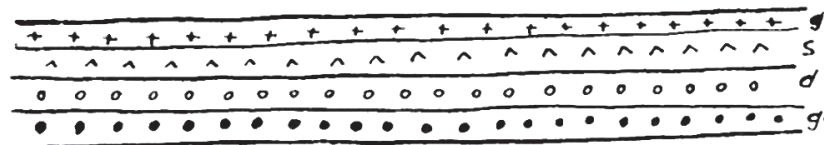

a

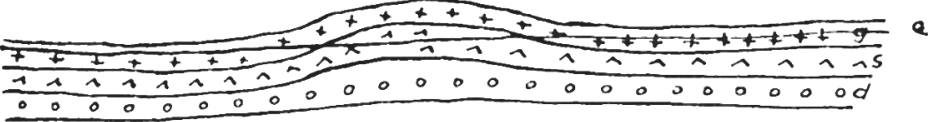

\section{Terciario:}
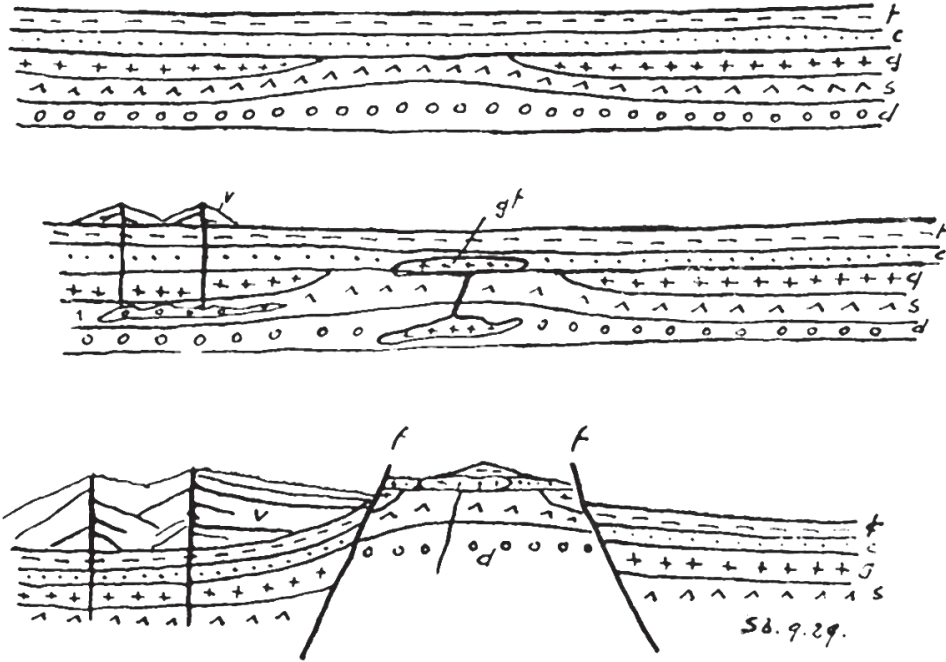

g granito, s sienita; diorita; ggabro; t terciario; c cretacico;
vrocas volcanicas conlava. f falla.
(3

Mioceno inf.

Mioceno sup.

Aluvio ${ }^{15}$

Fig. 2: Perfiles explicativos para la historia geológica de Costa Rica, según Schaufelberger (1929 a, b). Los números de cada perfil se adjuntaron en este trabajo.

miembros de la desaparecida Sociedad Geológica de Costa Rica. Probablemente, estuvieron realizando observaciones geológicas en diversos sitios del país, aún cuando sus trabajos tal vez nunca fueron publicados en los medios escritos de la época, tal es el caso de muchas observaciones geológicas efectuadas por José Fidel Tristán, que se guardan en el Archivo Nacional.
Este primer trabajo de Schaufelberger es un esfuerzo de divulgación significativo por llevar el conocimiento geológico de la época a las aulas de secundaria. Sin embargo, el análisis del trabajo muestra algunos aspectos de interpretación que actualmente dejan de tener sentido a la luz de los nuevos conocimientos que se tienen de la geología del territorio nacional. Dentro de este trabajo, se 


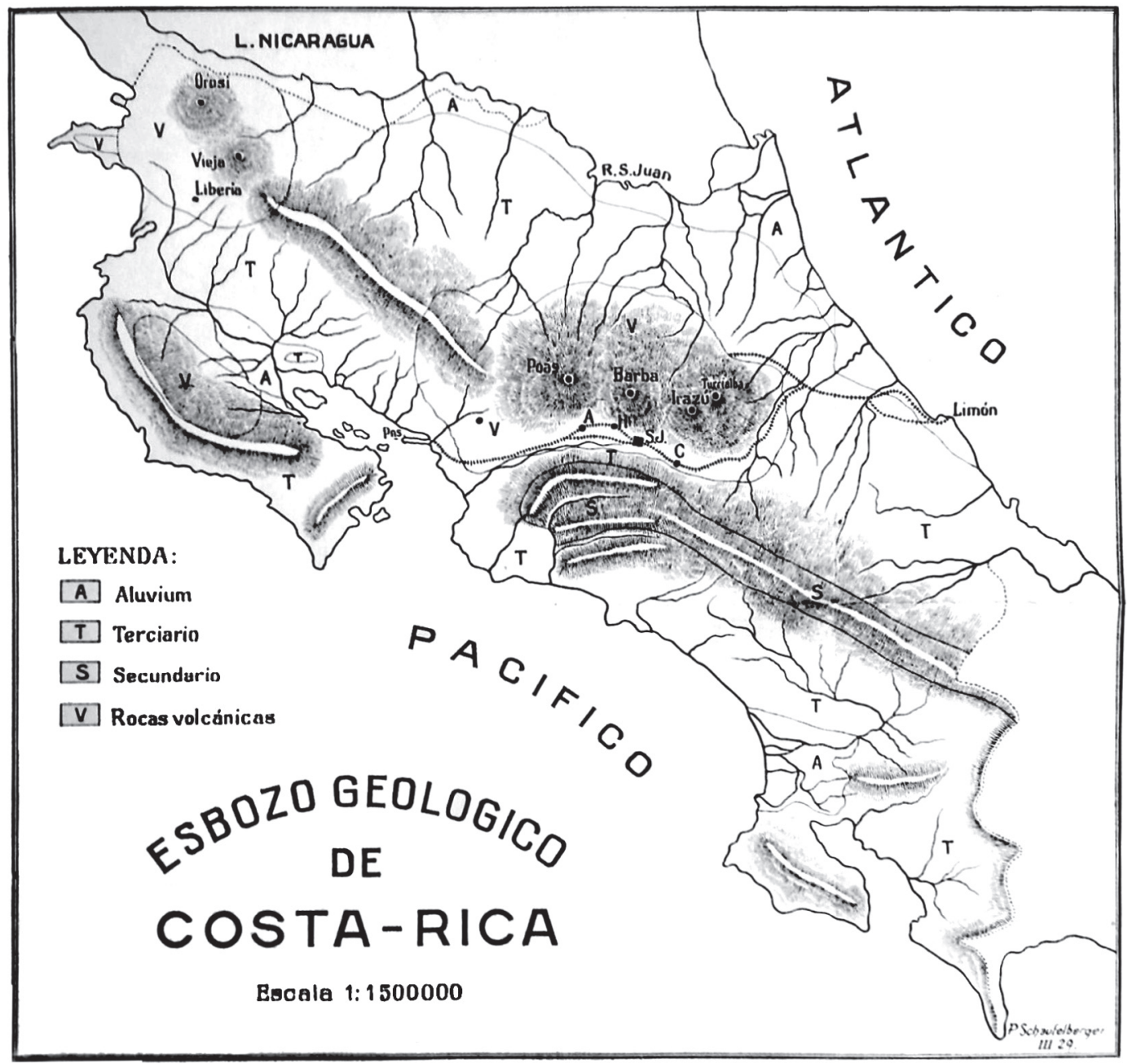

Fig. 3: Esbozo geológico de Costa Rica, publicado en 1929 por Imprenta Universal

destaca el esbozo geológico del país, que incorpora una serie de formaciones rocosas que van desde la era Secundaria al Cuaternario (Fig. 3) y una columna estratigráfica general para Costa Rica, en donde ubica rocas del Primario (Fig. 4).

El mapa de Sapper (Fig. 5) no remite formaciones geológicas a la era Primaria (conocida actualmente por Paleozoico) mientras que Schaufelberger,en la Columna estratigráficageneral para Costa Rica de las "Tablas Mineralógicas y Geológicas", sí incorpora esta era como presente en nuestro territorio. En Costa Rica nunca se han encontrado rocas del Paleozoico, pues es un territorio joven en donde la datación más antigua nos lleva al Jurásico Medio, en sedimentos de depositación oceánica profunda.

Por otra parte, el mapa de Sapper no reconoce en la península de Nicoya rocas volcánicas, mientras que Schaufelberger sí las ubica en su Esbozo Geológico, siendo así, que se refiere indirectamente al Complejo Ofiolítico de Nicoya, formado entre otros materiales, por lavas de composición basáltica. Inclusive, en el área que corresponde con la Península de Santa Elena, Schaufelberger reconoce la existencia de rocas ígneas (actualmente conocidas como las peridotitas de Santa Elena) de diferente naturaleza a la del resto del material volcánico de Guanacaste, y 
Tabla estratig.ráfica de Costa Rica

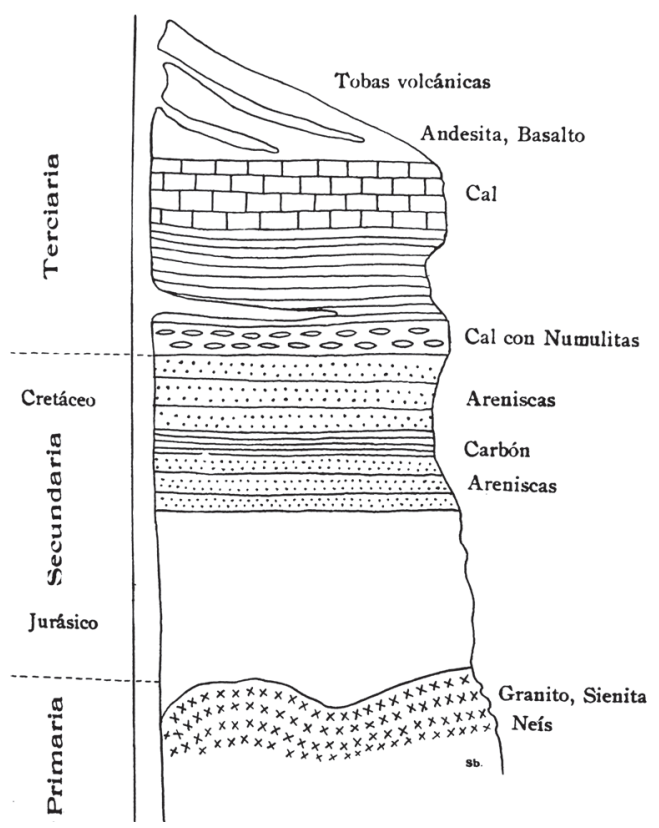

Fig. 4: Columna estratigráfica general para Costa Rica, publicada en 1929 por Imprenta Universal.

que dados los conocimientos de la época, no puede interpretar. Sin embargo, en forma juiciosa, las separa de aquellas rocas correspondientes a los edificios volcánicos actuales, queriendo muy posiblemente, demostrar con esta separación, el origen distinto de estos dos grupos de rocas.

Schaufelberger delimita en su Esbozo Geológico de Costa Rica, al eje de la Cordillera de Talamanca como constituido por rocas de la era Secundaria (actualmente Mesozoico) y que en la actualidad conocemos no van más allá del Terciario. Pero aún más llamativo, es el hecho de que en la tabla estratigráfica de Costa Rica, ubicada en las mismas "Tablas Mineralógicas y Geológicas" donde aparece el esbozo geológico del país, las rocas de la era Secundaria corresponden con areniscas y carbón, y no menciona rocas cristalinas como granitos, las cuales, actualmente sabemos son abundantes en los sectores de la Cordillera de Talamanca.

Por otra parte, posiblemente Schaufelberger desconoció para ese primer trabajo el "Mapa Geológico de Talamanca" elaborado por William M. Gabb a inicios de la década de 1870 , a pesar de que Denyer \& Soto (2000) refieren que el mapa sí fue conocido por Henri Pittier a finales del siglo XIX y por Luis Matamoros a inicios del siglo XX. En dicho mapa, Gabb describe el eje de la Cordillera de Talamanca como granítico con parches de rocas volcánicas, mientras que en sus faldas ubica rocas sedimentarias del Mioceno.

En relación a la pregunta que salta a la mente de si Schaufelberger conoció el mapa de Sapper al momento de realizar sus "Tablas Mineralógicas y Geológicas”, queda la incertidumbre, pues aún no es clara la fecha de publicación de ese mapa, tal y como lo mencionan Denyer \& Alvarado (2000), quienes cuestionan la fecha de su publicación: ¿1905 o 1937? Schaufelberger (1934) reporta la existencia de un mapa de Sapper publicado en Alemania en 1905 en la obra "Ueber Gebirgsbau und Boden des Suedlichen Mittelamerika", aunque pareciera que se trata de un mapa para toda Centroamérica Meridional y no exclusivamente para Costa Rica. De ser así, le corresponde a Schaufelberger ser el primero en mostrar un boceto geológico exclusivo de todo el territorio costarricense publicado en el país, y por lo tanto, de fácil acceso a toda la comunidad de la época. Para 1934, ya con un conocimiento mucho mayor de la geología del país, el Dr. Schaufelberger publica en sus "Apuntes de Geología" un mapa mucho más detallado y preciso que el mostrado en el año 1929 (Fig. 6).

Se sigue con la incertidumbre respecto a la mención por parte de Schaufelberger de rocas de la era Primaria. Trabajos anteriores no relacionan a esa era geológica con las formaciones litológicas del país. Por ejemplo, el trabajo de Gabb y su mapa geológico de Talamanca de 1873 (Denyer \& Soto, 1999) solamente reconoce rocas del Terciario, específicamente referidas al Mioceno para algunas formaciones sedimentarias de Talamanca y apoyado en dataciones paleontológicas que realizó (Denyer \& Soto, 2000).

Otras observaciones realizadas por Gabb en distintas áreas del país, no refieren en absoluto rocas del Primario. Por otra parte, el investigador Hill (1898) reconoció la posibilidad de la existencia de rocas del Cretácico, con base en análisis paleontogeográficos que realizó para el istmo centroamericano, sobre todo para la parte sureste del istmo, pero tampoco se refiere a rocas del Paleozoico. 


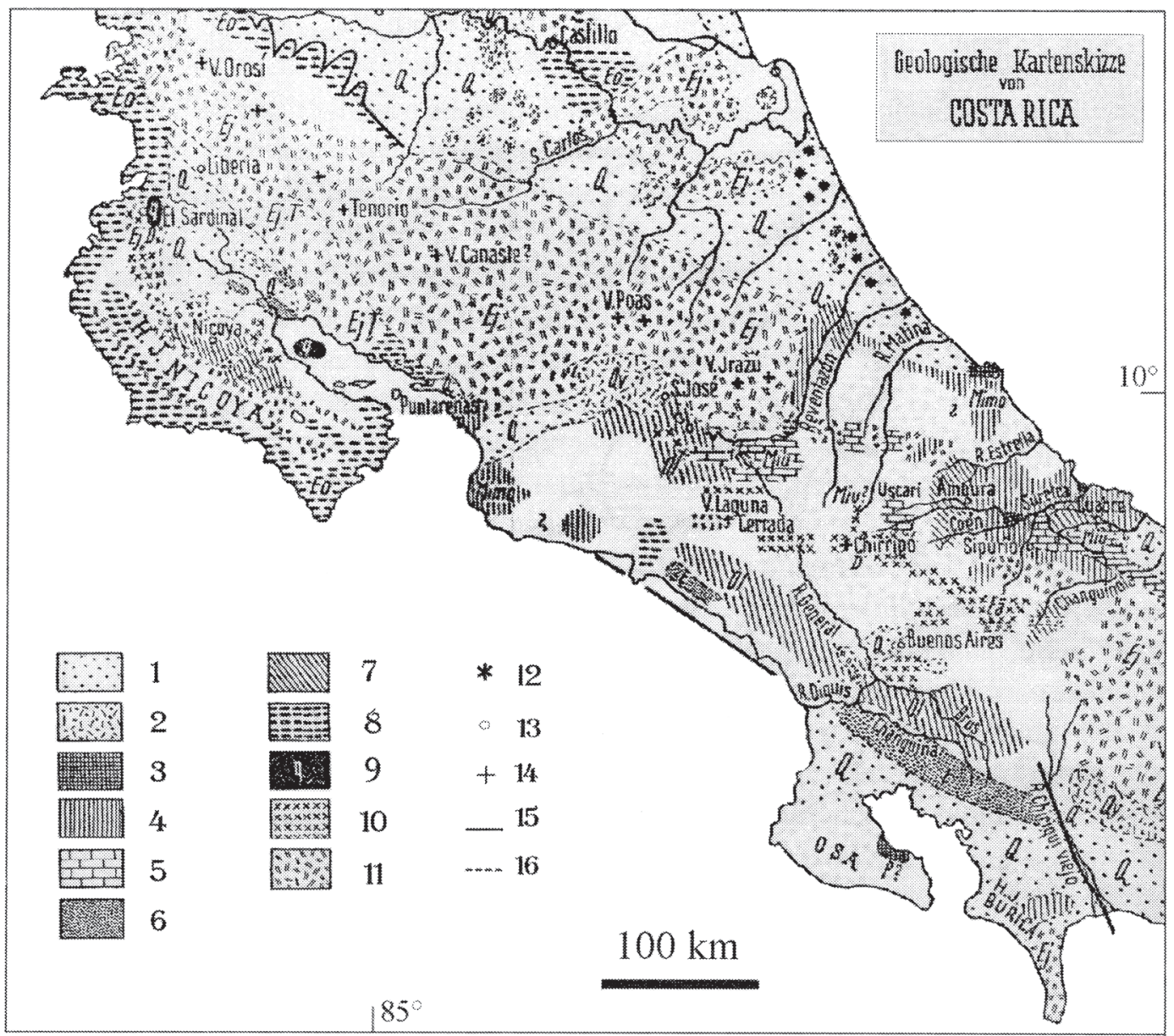

Fig. 5: Mapa geológico de Karl Sapper (Denyer \& Alvarado, 2000)

Como se mencionó anteriormente, dentro de las “Tablas Mineralógicas y Geológicas” se localiza una columna estratigráfica general para Costa Rica (Fig. 4). En esta columna Schaufelberger sugiere un basamento cristalino, formado por rocas ígneas y metamórficas como el gneis que ubica en la era Primaria. En la era secundaria (Mesozoico), predominantemente hacia el Cretácico, ubica rocas sedimentarias dentro de las que predominan las areniscas. Ubica también capas de carbón en el Cretácico, que hasta cierto punto y de acuerdo al conocimiento de la época, podría tratarse de la Formación Loma Chumico, constituida por lutitas silíceas en ocasiones negras, con presencia de restos de amonites y de edad cretácica, aunque esto queda como una especulación. Para el Terciario,
Schaufelberger representa en su columna estratigráfica una cobertura sedimentaria caracterizada por rocas calizas e inclusive, destaca la presencia de macroforaminíferos (Nummulites) dentro de algunas de estas rocas, lo cual permite una correlación directa con la Formación Fila de Cal (Las Ánimas) de edad Eoceno y que aflora en distintos puntos a lo largo de la vía del ferrocarril al Atlántico. Esta situación evidencia el hecho de que posiblemente Schaufelberger basó sus estudios geológicos en el análisis de los cortes ubicados a lo largo de las vías férreas del país.

Coronando los niveles sedimentarios del Terciario, Schaufelberger ubica una cobertura volcánica constituida por lavas andesíticas, basálticas y tobas que, sin embargo, no ubica dentro del 


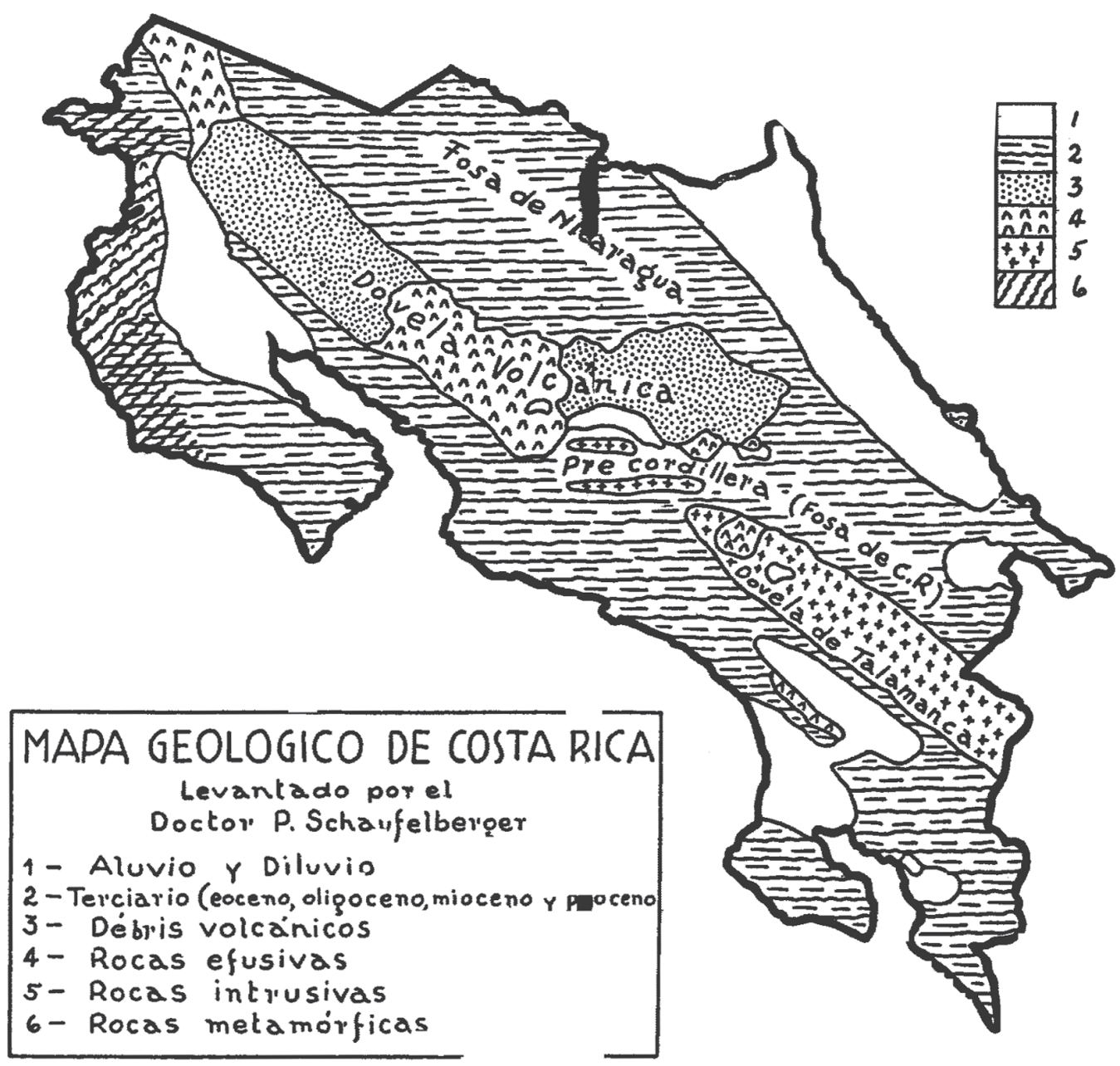

Fig. 6: Mapa geológico de Costa Rica confeccionado por el Dr. Schaufelberger en el año 1934.

Cuaternario, período durante el cual la actividad más importante para Costa Rica es la efusiva, reconociéndose actualmente una potente cobertura volcánica para este periodo.

En el perfil geológico que reproduce en las “Tablas Mineralógicas y Geológicas” (Fig. 7), Schaufelberger interpreta una secuencia estratigráfica soportada sobre un basamento primitivo. Sin embargo, sobresale el hecho de que en la garganta del Río Virilla también reconoce rocas primitivas intercaladas entre cenizas y lavas del Cuaternario. Se sugiere, como una posible explicación a esto, que las "lavas intracañón" (conocidas como Formación Colima") las haya interpretado como rocas primitivas.
No obstante las anteriores observaciones, se debe destacar el valor de las "Tablas mineralógicas y geológicas", pues fue su primer trabajo publicado en una fecha muy próxima a su arribo a Costa Rica.

\section{Perfiles geológicos de Costa Rica}

Los perfiles geológicos reproducidos en este artículo fueron rescatados de un grupo de documentos que una instancia nacional iba a desechar.

La elaboración de perfiles es el complemento indispensable de todo mapa geológico, donde el geólogo completa la visión tridimensional y donde plasma su interpretación sobre las relaciones 


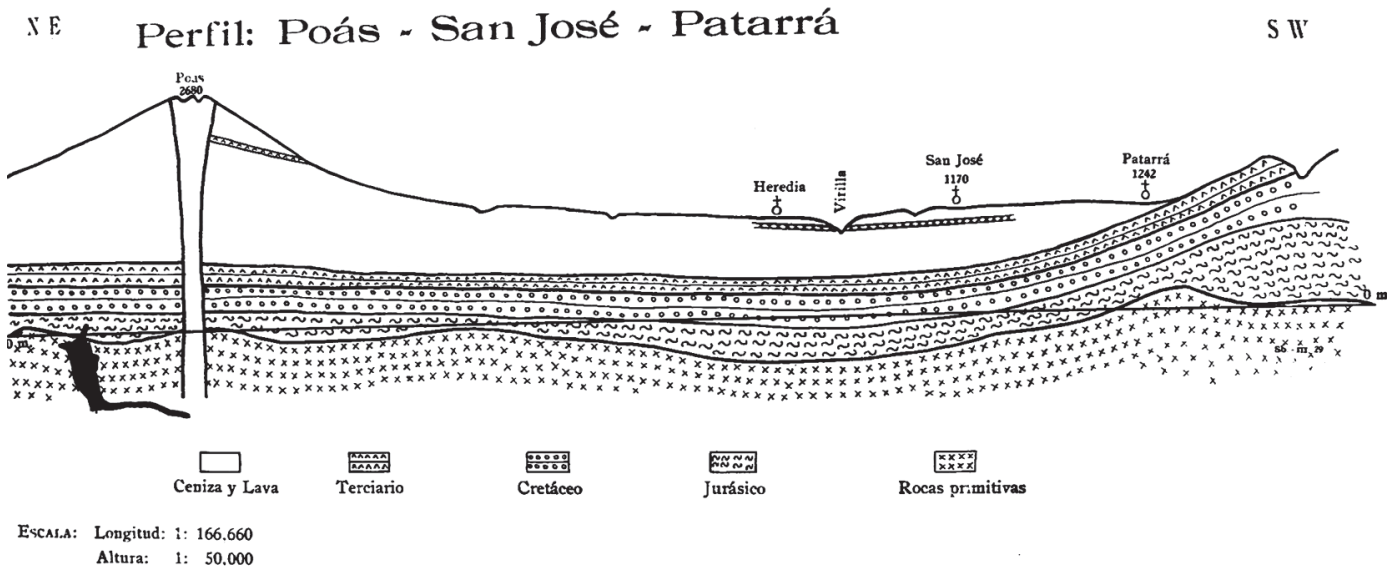

Fig. 7: Perfil geológico reproducido en las “Tablas mineralógicas y geológicas” de 1929. Imprenta Universal.

espaciales, temporales y estructurales de las diferentes formaciones descritas para una cierta área.

Después de los perfiles parciales de Romanes de 1912 y publicados por Denyer \& Alvarado (2000), son los perfiles interpretativos de Schaufelberger, los que marcan la pauta de la interpretación geológica de comienzos de la década de 1930.

Para la confección de estos perfiles, posiblemente estudió los cortes de taludes de las dos vías férreas, pues dos de sus perfiles los extiende desde Las Lomas en el Caribe hasta San José y otro perfil lo extiende desde San José hasta Puntarenas. Las poblaciones que refiere en dichos perfiles son en su mayoría estaciones en las rutas férreas. También debemos recordar que para la confección de perfiles se necesita de una detallada base cartográfica, inexistente por aquella época, de allí que la topografía sea generalizada.

\section{Perfil Las Lomas - San José}

En el perfil Las Lomas - San José (Fig. 8, verlo completo en el repositorio), se reconocen la secuencia sedimentaria del Terciario, mostrada mediante guiones; sobre ella descansa la cobertura volcánica del Cuaternario, mostrada con puntos, y sobre esta unidad volcánica se ubica lo reciente: el aluvión. Hasta aquí el perfil muestra la realidad geológica de la región estudiada: mucha roca sedimentaria del Terciario, tales como las formaciones Senosri (Eoceno-Oligoceno), Fila de Cal (Eoceno Medio a Superior), Uscari (Mioceno Medio a Superior) y Suretka (Plioceno - Pleistoceno) (Linkimer \& Aguilar, 2000).

En las cercanías de Tres Ríos reconoce rocas sedimentarias del Terciario que pueden ser asociadas con la formación Coris. Debajo de las rocas terciarias interpreta rocas del Cretácico (posiblemente pertenecientes a la Formación San Miguel), de tal forma que por escala aparecen como rocas de poco espesor y por debajo de estas, muestra rocas ígneas. Lo curioso es que en la región únicamente han sido reconocidos por Cervantes (1989) que describe como lavas de naturaleza calcaoalcalina, en almohadilla. Tournon \& Alvarado (1997) reconocen basaltos en almohadilla posiblemente del Cretácico superior al Paleoceno y estas afloran en la cuenca media del río Pacuare, al este de Las Lomas. Con relación a las rocas ígneas mostradas, no aclara si son del Primario o del Secundario. La simbología usada por Schaufelberger indicaría que posiblemente estas rocas ígneas corresponden con intrusivos. Asocia a estas rocas un moderado plegamiento, algunos de ellos bastante simétricos.

Para el Cuaternario reconoce algunas formaciones lávicas representadas como manchas negras, puntuales, dando la idea de cuerpos intrusivos y ubica en Las Lomas una terraza erosiva, que podría corresponder a los deslizamientos que desde el principio de la construcción de la vía férrea empezaron a 


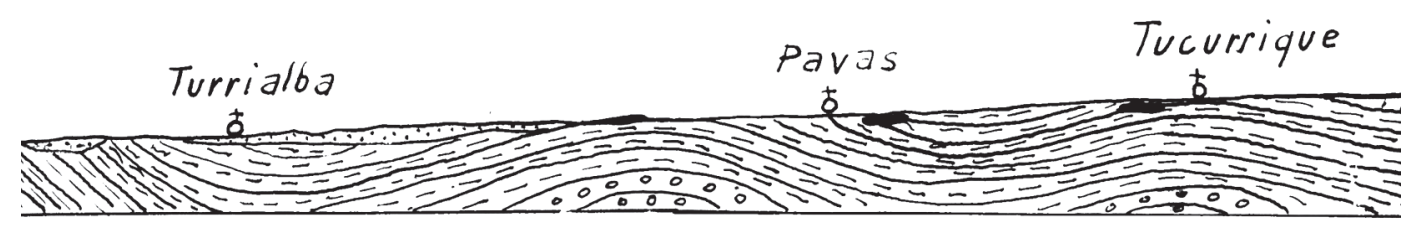

Fig. 8: Perfil Las Lomas - San José, escala 1:50 000. Confeccionado posiblemente en 1930.

reactivarse, resultando en serias consecuencias para el adecuado funcionamiento del ferrocarril al Caribe (Peraldo \& Rojas, 1998).

\section{Perfil San José - Puntarenas}

El perfil San José - Puntarenas (Fig. 9, verlo completo en el repositorio) también exhibe la falta de base cartográfica, pues su topografía es idealizada. En este perfil no aparece el Cretácico, sino el Terciario y el Cuaternario. Con base en la visión geológica de la época, se hace una división entre rocas ígneas y volcánicas.

Desde San José hasta Siquiares en Alajuela, representa la cobertura volcánica que hoy sabemos está formada por avalanchas, lahares e ignimbritas con algunas coladas lávicas. Cerca de

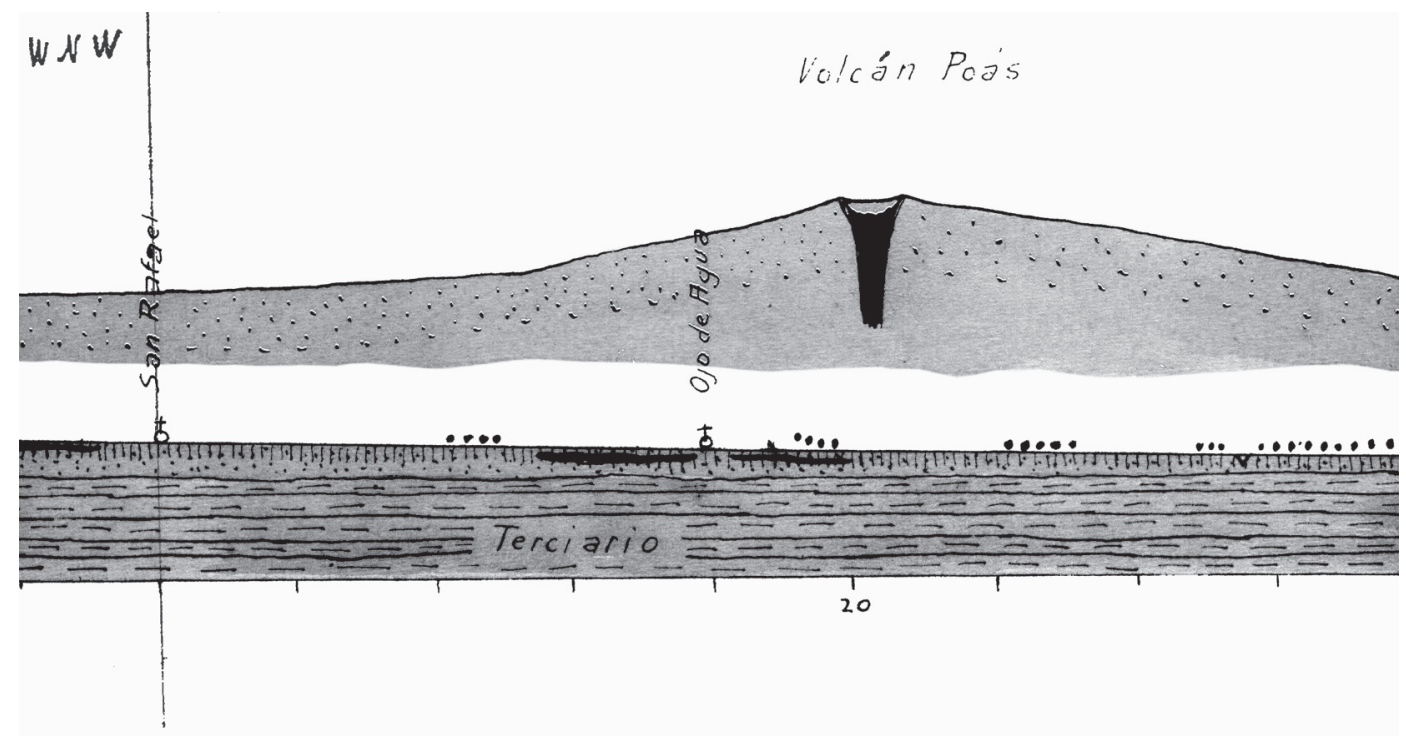

\section{Serie de arenisca de Purta de Carbó}

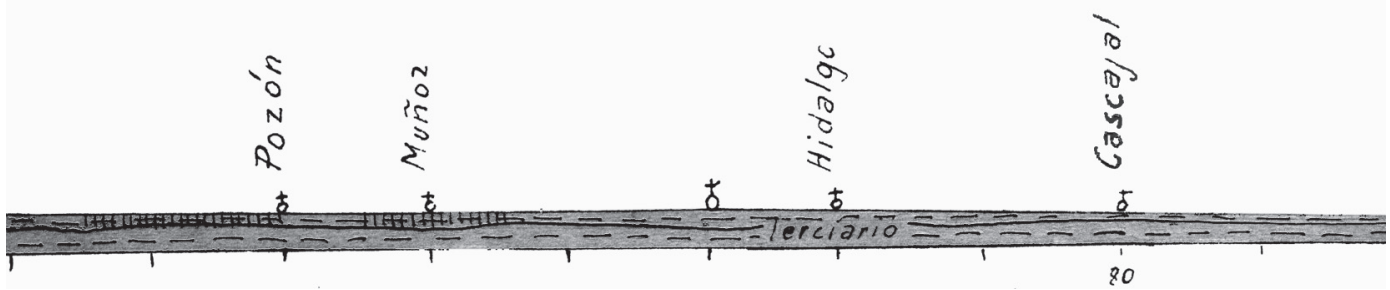

Fig. 9: Perfil San José - Puntarenas, escala 1:50 000. Confeccionado en mayo de 1930. 
Turrúcares afloran en el perfil rocas sedimentarias del Terciario, como efectivamente afloran en San Miguel de Turrúcares y alrededores, que corresponden a rocas sedimentarias calcáreas del Terciario (Formación Turrúcares).

Ya propone fallas que corresponden a límites entre las unidades del Terciario y el volcánico. Es difícil ubicar con claridad esas fallas, pues la región está fuertemente tectonizada. ¿Corresponderá alguna de estas dos fallas con la falla Garita?

Ubica entre Hacienda Vieja y Barranca, en el Pacífico Central, la serie de arenisca de Punta Carballo definidas así por McDonald (1920-1921).

\section{Perfil del Macizo Volcánico de Costa Rica}

Para el sector central de Costa Rica, con un rumbo aproximado NW-SE, Schaufelberger elabora un perfil geológico que atraviesa los principales edificios volcánicos de la cordillera volcánica Central (Fig. 10, verlo completo en el repositorio). Schaufelberger interpreta la existencia de un basamento constituido por rocas ígneas a las que, sin embargo, no asigna rangos de edades, pero están por debajo de las rocas del Cretácico. Por la simbología usada, podrían corresponder con intrusivos. Sobreyaciendo este basamento y representada mediante líneas, ubica una cobertura delgada de rocas cretácicas, sobre las cuales, desgraciadamente no especifica el tipo de roca. Una extensa y espesa secuencia de rocas terciarias es ubicada por Schaufelberger sobre las rocas cretácicas, y de acuerdo con la interpretación y los límites aproximados del perfil, se extenderían en forma continua a lo largo de todo el perfil. De acuerdo con la simbología usada por Schaufelberger para estas rocas terciarias, posiblemente se trate de rocas carbonatadas, de tal manera que puede establecerse una posible correlación en el sector SE con las rocas carbonatadas de la Formación Fila de Cal (Las Ánimas) que efectivamente presenta edades ubicadas dentro de la era Terciaria (Eoceno Medio-Superior). La ubicación de estas rocas en el sector SE es perfectamente comprensible, si consideramos la gran cantidad de afloramientos ubicados a lo largo de la vía del ferrocarril y que muy posiblemente Schaufelberger interpoló a la hora de realizar el perfil. Con respecto a los niveles de la era Terciaria que se ubican en el sector NW del perfil, resultan más contradictorios ya que, en general la cobertura volcánica del Cuaternario es la que predomina en estos sectores. No obstante, cabe la posibilidad de que tales rocas tengan relación con la Formación Venado, de edad Mioceno Medio - Mioceno Tardío (también era Terciaria),

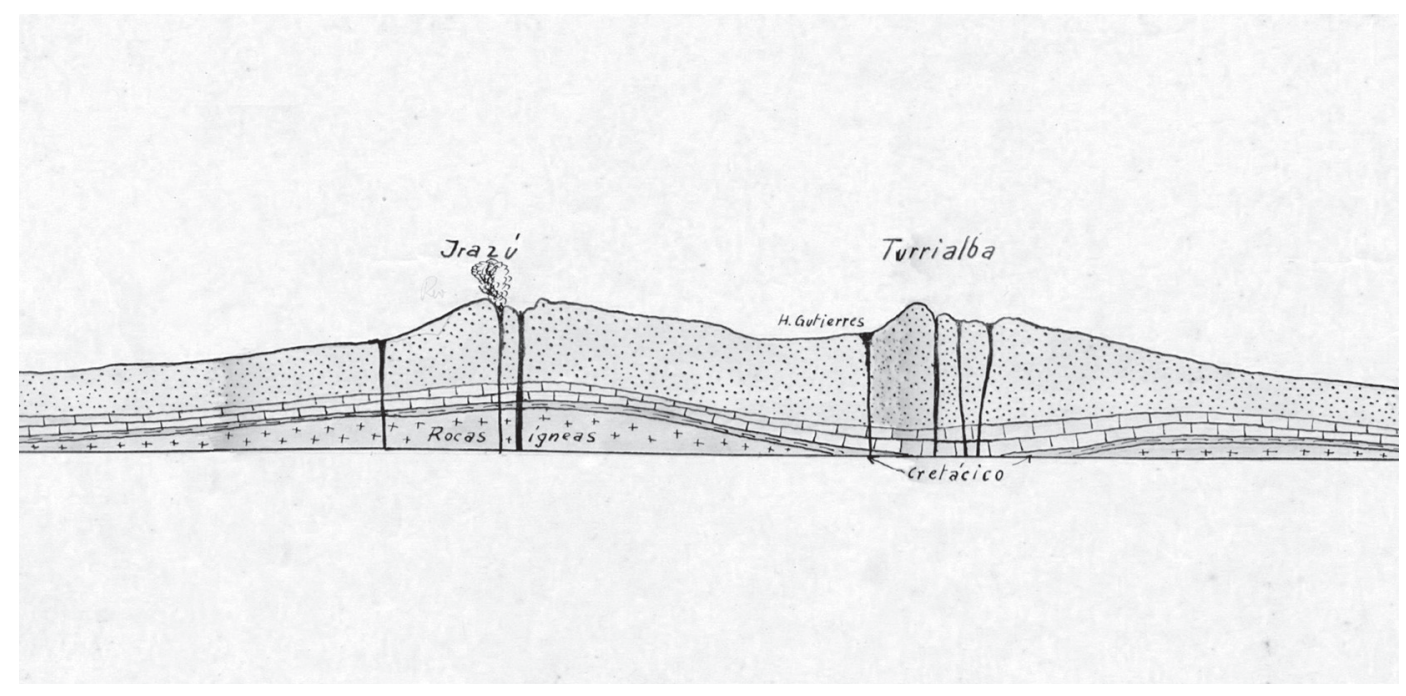

Fig. 10: Segmento del perfil a lo largo de la cordillera volcánica Central (el perfil completo se localiza en el Repositorio correspondiente a este artículo) 
que unido a su composición calcárea, pudieron llevar a Schaufelberger a correlacionarlas con aquellas de la Formación Fila de Cal.

Finalmente, sobreyaciendo toda la secuencia anterior, Schaufelberger ubica la espesa secuencia correspondiente a los edificios volcánicos recientes, que de acuerdo a su interpretación, se encuentra constituida principalmente por cenizas, tobas y lavas. Sobresale la complejidad de las estructuras volcánicas existentes, en las que indica por ejemplo, la existencia de cráteres parásitos, e inclusive, en el caso de las Tres Marías, la relación directa entre estos cráteres y las denominadas "Lagunas de Heredia". Resulta interesante cómo Schaufelberger acerca a su línea de perfil las estructuras de los cerros Zurquí y Viejo y les asigna correctamente la simbología volcánica, evidenciando así, el conocimiento que para la época tenía sobre estos.

Otro dato rescatable del perfil es el hecho de que mediante su simbología, se puede interpretar para el año de 1930 (fecha de elaboración del perfil), la existencia de algún tipo de actividad volcánica, tanto en la "Laguna Caliente" del volcán Poás como en el volcán Irazú, última que es representada con una mayor magnitud. En las demás estructuras de origen claramente volcánico, no destaca ningún tipo de actividad.

\section{LABOR EN CHINCHINÁ, COLOMBIA}

Como se indicó, una vez que no hubo más contratos firmados por Schaufelberger con el Gobierno de la República, este viajó posiblemente en el transcurso de 1938 a Colombia, a laborar con la Federación Nacional Cafetalera, ubicada su sede en Chinchiná. Fue contratado por el Gerente Técnico de la Federación Nacional Cafetalera (ver Apéndice 1), quien lo contactó aquí en Costa Rica para que laborara con ellos en Colombia, debido a que por esa época existían muchos problemas agronómicos en el café. De aquí salta la inquietud sobre la verdadera profesión de Schaufelberger como geólogo o agrónomo con especialidad en geología.

El Dr. Schaufelberger laboró en Colombia aspectos de geología y suelos. Se conocen algunas obras de él publicadas en Colombia sobre diversos aspectos de su ciencia. Uno de los primeros trabajos que se lograron conocer por referencias bibliográficas únicamente es un trabajo titulado "Apuntes geológicos y pedagógicos de la zona cafetera de Colombia". Este trabajo fue publicado en Manizales en la Imprenta Oficial en el año de 1944 y tiene a Schaufelberger como único autor. Analiza la geología general, estratigrafía y la tectónica de Colombia. Este libro tiene un suplemento que hace referencia a la genética y clasificación de los suelos tropicales.

Otra obra que se logró localizar por referencias bibliográficas se denomina "La formación y las series de suelos de la zona cafetera de Colombia", publicado en 1947 en la Revista del Centro Nacional de Investigaciones del Café (CENICAFE) Chinchiná, Caldas (vol 1, no. 2, sept. 1947). Finalmente se localizó el trabajo titulado "Los problemas de los suelos tropicales y su solución", publicado en la revista del CENICAFE tomo 14, de Caldas, Colombia en el año de 1963.

El Dr. Jorge León lo conoció en Chinchiná a inicios de la década de 1960 y refiere que ya en ese tiempo el Dr. Schaufelberger estaría sobre los 70 años. Comenta que ya estaba retirado, pero vivía en la casa de Chinchiná que la Federación le asignó.

\section{COMENTARIOS FINALES}

Los comentarios que se han hecho en torno a los trabajos del Dr. Schaufelberger consideran de gran importancia su labor, digna de rescatarse del paso del tiempo, y entender que con la poca información y la escasa infraestructura dedicada a la investigación científica, además de los arcaicos recursos tecnológicos, y la limitante que significó la escasez de vías de comunicación y transporte, este pionero dejó un gran aporte, donde las diferencias encontradas, no hay que considerarlas errores, sino consecuencias de la interpretación, basada en el conocimiento de la época y de la percepción del investigador, respecto a lo que posiblemente existiera bajo la gruesa cobertura de sedimento terciario del país.

La interpretación del Dr. P. Schaufelberger no está del todo errada, pues a una determinada profundidad, deberíamos encontrar el basamento de Costa 
Rica, que corresponde al Cretácico-Paleoceno según sea el área donde estemos analizando la geología. No obstante, aquí no es importante saber dónde se equivocó o dónde acertó, sino considerar este trabajo pionero como una base de información importante, a partir de la cual, muy posiblemente otros estudios geológicos posteriores partieron y llegaron a confirmar o mejorar el conocimiento de la geología del país.

\section{AGRADECIMIENTOS}

Se desea agradecer a la señora Doris Wälchli Giraud, jefa alterna de misión de la Embajada Suiza en Costa Rica, por investigar los datos personales del Dr. Paul Schaufelberger, mediante sus contactos en la Embajada Suiza en Colombia. Al Dr. Jorge León Arguedas por facilitarnos documentación valiosa respecto a las publicaciones del Dr. Schaufelberger y por concedernos tiempo para efectuar la entrevista realizada.

\section{REFERENCIAS}

ALVARADO, G.E., MORALES, L.D. \& SOTO, G.J., 1991: Historia del desarrollo de las ciencias geológicas en Costa Rica.- En: RUIZ, A. (ed.), 1991: Ciencia y Tecnología. Estudio del pasado y el futuro. Ed.Guayacán, San José, Costa Rica: 121-141.

ALVARADO, G.E. \& PERALDO, G., 2003: Los primeros pasos de la geología en la Costa Rica del siglo XIX. En: PERALDO, G. (comp.): Ciencia y técnica en la Costa Rica del siglo XIX. Ed. Tecnológica de Costa Rica, Cartago: 209-236.

CASTILLO, S. \& PERALDO, G., 2000a: Reseña histórica de la Escuela de Geología.-Inf. Sem. IGN, 36: 97-122.

CASTILLO, S. \& PERALDO, G., 2000b: La creación de la Escuela y la carrera de Geología.En: DENYER, P. \& KUSSMAUL, S., (comps.): Geología de Costa Rica. Ed. Tecnol. Costa Rica, Cartago: 493-498.

CERVANTES, J.F., 1989: Base geológica para los análisis geotécnicos del proyecto hidroeléctrico Siquirres, Provincia de Limón, Costa Rica.- 117 págs. Esc. Cent. Geol. Universidad de Costa Rica [Tesis Lic.].

CROSBY, I.B., 1945: Geología del cañón del río Virilla, en la Meseta Central occidental de Costa Rica.- El Agricultor Costarricense, 49: 1-19.

DENYER, P. \& ALVARADO, G.E., 2000: Desarrollo y evolución de la geología.- En: DENYER,P.\& KUSSMAUL, S. (comps.): Geología de Costa Rica. Ed. Tecnol. Costa Rica, cartago: 471-492.

DENYER,P.\& SOTO, G.J., 1999: Contribución pionera de William M. Gabb a la geología y cartografía de Costa Rica.- Anuario de Estudios Centroamericanos 25(2): 103-138.

DENYER, P. \& SOTO, G.J., 2000: Análisis de los trabajos geológicos de William M. Gabb sobre Costa Rica, a la luz del paradigma geológico del siglo XIX.- Rev. Geol.. Amér. Central, 23: 97-118.

FERNÁNDEZ, M., 1993: Desarrollo histórico de las actividades geológicas en Costa Rica hasta la creación del Colegio de Geólogos.Memoria IV Congreso Geológico Nacional 28 de junio al 3 de julio: 12 .

GOBIERNO DE COSTA RICA, 1931: Colección de leyes y decretos, segundo semestre de 1930. 351 págs. Imprenta Nacional, San José.

GOBIERNO DE COSTA RICA, 1936: Colección de leyes y decretos, primer semestre de 1936.- 320 págs. Imprenta Nacional, San José. 
GOBIERNO DE COSTA RICA, 1938: Colección de leyes y decretos.- 320 págs. Imprenta Nacional, San José.

HILL, R.T., 1898: The geological history of the Isthmus of Panama and Portions of Costa Rica.- Bulletin of the Museum of Comparative Zoology, 28(5): 1-283.

LINKIMER, L. \& AGUILAR, T., 2000: Estratigrafía sedimentaria.- En: DENYER, P. \& KUSSMAUL, S. (comps.): Geología de Costa Rica. Ed. Tecnol. Costa Rica, Cartago: 43-62

LEÓN, J., 2003: La exploración botánica de Costa Rica en el siglo XIX.- En: PERALDO, G., (comp.): Ciencia y Técnica en la Costa Rica del siglo XIX. Ed. Tecnol. Costa Rica, Cartago: 129-186.

MCDONALD, D., 1920-1921: Informe final geológico y geográfico de Costa Rica.- Rev. Costa Rica 2:28-32, 50-57, 106-111, 139-148.

PERALDO, G. \& ROJAS, E., 1998: La deslizable historia del ferrocarril al Caribe de Costa Rica.- Anuario de Estudios Centroamericanos, 24(1-2): 97-128.

PORRAS, D., 1988: Liceo de Costa Rica, 100 años: Álbum de recopilación fotográfica.489 págs. Imprenta Talleres Trejos Hnos. Suc., S.A, San José.

ROMANES, J., 1912: Geology of a part of Costa Rica.- Quaterly J. Geol. Soc. London 68: 103-139.

SCHAUFELBERGER, P., 1929a: Una noticia sobre la geología de Costa Rica: un perfil del Pacífico al Atlántico.- Revista del Colegio Superior de Señoritas, 1(10): 1-12.

SCHAUFELBERGER, P., 1929b: Tablas mineralógicas y geológicas.- 20 págs.Imprenta Universal, San José, Costa Rica.
SCHAUFELBERGER, P., 1934: Apuntes de Geología: La necesidad de un mapa geológico de Costa Rica y su importancia para la industria cafetalera.- 7 págs. Imprenta Borrasé, San José, Costa Rica.

TOURNON, J. \& ALVARADO, G.E., 1997: Mapa geológico de Costa Rica. Escala 1:500 000.-79 págs. + mapa geológico. Ed. Tecnol. Costa Rica, Cartago.

VENTURA, A.C. \& SIBAJA, P., 1991: Emigración suiza a Costa Rica.- 51 págs. Master Litho S.A., San José.

\section{APÉNDICE}

Entrevista con el Dr. Jorge León Arguedas sobre P. Schaufelberger.

El botánico Dr. Jorge León Arguedas, trabajó durante largo tiempo en el Instituto Interamericano de Ciencias Agrícolas (IICA), atendiendo principalmente asuntos relacionados con la actividad cafetalera. Las distintas actividades desarrolladas por el Dr. Jorge León involucraban viajes a distintos países, entre ellos Colombia, lugar en el que tuvo a principios de la década de 1960, un encuentro casual con Paul Schaufelberger, con quien habló unos instantes, y por eso, se quiere reproducir la entrevista que a raíz de ese encuentro se le hizo a don Jorge. Se reproduce tal como se realizó respetando las pausas que el entrevistado hizo. Esta entrevista la realizaron los autores de este artículo. A continuación la entrevista:

Jorge León: "Yo tenía que viajar a menudo por asuntos de trabajo. Yo trabajaba en Lima, Perú, teníamos una serie de proyectos en distintas partes y eso con el IICA. Una vez era para establecer un programa interamericano de café en Colombia, el país [Costa Rica] había sido designado, entonces yo viajé a menudo. No!, no se pudo hacer el proyecto por motivos varios y en uno de esos viajes fue cuando yo lo conocí, a Schaufelberger, ya estaba viejo...

Entrevistador: ¿Qué edad tenía?, más o menos.

Jorge León: ¡Quién sabe!, ya tendría más... [duda, pensando] bien pasados de los setentas 
creo yo. Vivía en una casita muy pequeña en la propia estación, que era una cortesía de la estación [experimental en Chinchiná]. Ya lo habian retirado [pausa] porque él estaba retirado, pero el vivió ahí por los años que le faltarían, lo que no he podido averiguar es si se murió ahí o no. Solemond [un empleado de la estación experimental], colombiano, que trabajaba en esa estación, pero que no me pudo dar razón porque él se había salido [pausa], ido antes, el trabajaba ahí, don Pablo estaba pero en... [pausa] ya él se vino antes, y no me pudo dar detalles [Solemond]. Yo supongo que él moriría ahí [se refiere al Dr. P. Schaufelberger] y ahí quizá lo enterraron, o sea es un pueblo que se llama Chinchiná, donde está la estación experimental. Está cerca de Armero. ¿Se acuerda de la gran avenida? [nos pregunta, hace alusión al lahar de Armero de 1985] La avenida llegó hasta la estación experimental, es la zona más concentrada de producción de café de Colombia, ahi está la estación, y ahí está todavía y seguirá...

De manera que hablé con él [con P. Schaufelberger] y me contó varias cosas, así, no recuerdo, exactamente, no estaba muy bien para hablar, y me regaló una cuestioncita ahí, que no sé dónde la tengo, es una separata, de un artículo no de él, sino de otro sobre Costa Rica, pero voy a buscárselo y se lo enseño luego, de manera que fue una cosa así, muy por encima apenas, y después como no se pudo establecer el programa en Chinchiná, entonces no volví más, de manera que no supe mucho.

Entrevistador: Eso fue ¿en qué año?

Jorge León: No lo puedo recordar ahora, yo estuve en el 61, del 61 al 63 a cargo de esas cosas, ahora una cuestión que ahí, yo creo que serviría para algo, es lo siguiente, yo estaba viendo que el último artículo que escribió él [se refiere al Dr. P. Schaufelberger], aquí en Costa Rica, salió en enero de 1937. Ahora, yo llegué al Museo Nacional a trabajar en el 41, en ese espacio de cuatro años, en ese espacio fue cuando él se fue de aquí, cuando yo llegué al Museo, estaba a cargo de Geología Alfonso Segura Paguagua. Él [se refiere al geólogo Segura Paguagua] ya tendría como un año de estar ahí, tal vez más, de tal manera que quizás del 37 al 40 fue cuando se fue [se refiere al Dr. P. Schaufelberger], yo supe alguna vez, así, que quien lo había contratado era el gerente técnico de la Federación de Cafetaleros de Colombia, Ramón [pausa para pensar], bueno este señor parece que venía aquí en visitas. En esa época había mucho precario por asuntos de los problemas de café, problemas digamos puramente agronómicos, entonces el me parece que fue el contacto que lo contrató, entre esos dos años entre 37 y 40 fue que este hombre se fue de aquí [se refiere al Dr. P. Schaufelberger]." 